TEKNIK NOT 



\title{
Betonarme Kesitlerin Kapasite Momentlerinin Yaklaşık Hesabı
}

\author{
Ŭgur ERSOY 1 \\ M. Emre ÜNAL ${ }^{2}$
}

Öz

$\mathrm{Bu}$ çalışmada betonarme kiriş ve kolon kesitlerinin kapasite momentlerinin yaklaşık hesabı için Deprem Yönetmeliği’nde yer alan öneriler tartışılmaktadır. Bu öneriler kullanılarak hesaplanan yaklaşık moment kapasiteleri daha gerçekçi, daha kesin hesaplarla elde edilenlerle karşılaştırılıp irdelenmektedir.

Anahtar Kelimeler: Betonarme, kiriş, kolon, kapasite momenti, yaklaşık hesap.

\begin{abstract}
Approximate Methods for Calculating Capacity Moments of Beam and Column Cross Sections

Recommendations are made in the Turkish Seismic Code for calculating approximate moment capacities of reinforced concrete beam and column cross-sections. Moments obtained using these recommendations are compared with those calculated using more exact methods.
\end{abstract}

Keywords: Reinforced concrete, beam, column, capacity moment, approximate moments.

\section{GİRiş}

$\mathrm{Bu}$ çalışmada kiriş ve kolon kesitlerinin kapasite momentlerinin yaklaşık olarak saptanmasına yönelik Deprem Yönetmeliği'nde yer alan öneriler irdelenmektedir. Bu önerilerle elde edilen kapasite momentleri, çok daha gerçekçi yöntemlerle hesaplananlarla karşılaştırılmaktadır[1]. Bu çalışmada kiriş ve kolon kesitinlerinin daha kesin kapasite momentleri $\left(\mathrm{M}_{\mathrm{p}}\right)$, Deprem Yönetmeliği’nde öngörülen sargı donatısına sahip kesitler için, donatıdaki pekleşme dikkate alınarak hesaplanmaktadır. Kapasite momentinin hesabında "SARGILI.xls" yazılımı kullanılmıştır[2]. Bu yazılımda sargılı ve sargısız beton için Kent

\footnotetext{
Not: Bu yaz1

- Yayın Kurulu'na 06.12.2017 günü ulaşmıştır. 31.01.2018 günü yayımlanmak üzere kabul edilmiştir.

- 30 Kasım 2018 gününe kadar tartışmaya açıktır.
}

- DOI: $10.18400 /$ tekderg.369100

1 Boğaziçi Üniversitesi, İnşaat Mühendisliği Bölümü, İstanbul - ugur.ersoy@boun.edu.tr

2 Boğaziçi Üniversitesi, İnşaat Mühendisliği Bölümü, İstanbul - emre.unal@boun.edu.tr 
ve Park modelleri kullanılmıştır. Donatı çeliği için ise pekleşmeli elasto-plastik model kullanılmış, pekleşmenin 0.01 birim deformasyonda başladığı varsayılmıştır.

\section{DİKDÖRTGEN KİRIŞ KESITLERININ KAPASITE MOMENTİ Mp'NİN YAKLAŞIK HESABI}

Deprem Yönetmeliğinde kirişlerdeki en büyük kesme kuvveti hesaplanırken düşey yükün yanı sıra iki uçtaki momentlerin de dikkate alınması gerekmektedir[1]. Doğal olarak kirişte oluşan en büyük kesme kuvveti hesaplanırken kiriş uçlarında oluşacak momentlerin de maksimum olması gerekir. Başka bir deyişle sözü edilen moment, sarg1 etkisi ve pekleşmeyi de içeren beton ve çelik modellerinin kullanıldığı yazılımlardan elde edilen moment-eğrilik ilişkilerinden belirlenen en büyük moment olmalıdır. "Kapasite Momenti” olarak tanımlanan bu moment $\mathrm{M}_{\mathrm{p}}$ olarak gösterilecektir.

Deprem yönetmeliğinde kapasite momentinin yaklaşık olarak taşıma gücü momenti 1.4 ile çarpılarak elde edilebileceği belirtilmektedir[1]. Şekil-1'de moment-eğrilik ilişkisinden elde edilen kapasite momentinin, taşıma gücü momentine oranının $\rho^{\prime} / \rho$ oranı ile değişimi gösterilmiştir.

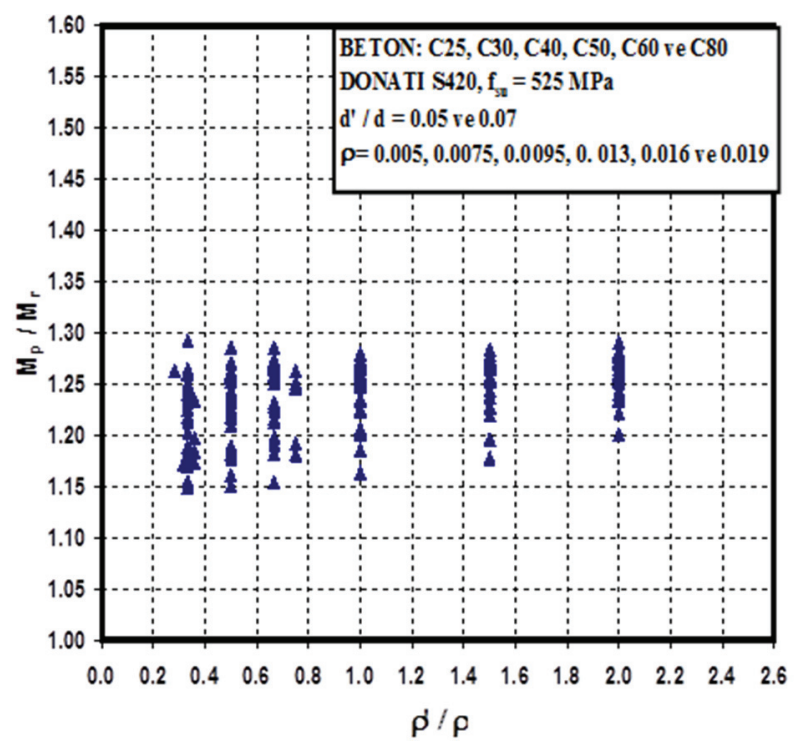

Şekil 1. $M_{p} / M_{r}$ oranının $\rho^{\prime} / \rho$ oranı ile değişimi

Şekil-1'in oluşturulmasında altı beton sınıfı, altı çekme donatısı oranı dikkate alınmıştır. Görüldüğü gibi $\mathrm{M}_{\mathrm{p}} / \mathrm{M}_{\mathrm{r}}$ oranı 1.15 ile 1.3 arasında değişmektedir. $\mathrm{M}_{\mathrm{r}}$, kiriş kesitinin malzeme hesap dayanımları kullanılarak hesaplanan taşıma gücü momentidir. $\mathrm{Bu}$ durumda yönetmelikteki 1.4 çarpanının fazla güvenli tarafta kaldığı sonucuna varılabilir. Ancak Deprem Yönetmeliği'nde donatı çeliğinin deneysel olarak bulunan ortalama akma dayanımının, ilgili çelik standartlarında öngörülen karakteristik akma dayanımının 1.3 
katından daha fazla olamayacağı belirtilmektedir[1]. Kapasite momenti oluşabilecek en büyük moment olarak tanımladığından, donatı akma dayanımında izin verilen bu artış dikkate alınmalıdır. Şekil-2'deki $\mathrm{M}_{\mathrm{p}}$ değerleri $\mathrm{f}_{\mathrm{y}}=1.3 \mathrm{f}_{\mathrm{yk}}$ temel alınarak hesaplanmıştır.

Şekil-2'de görüldüğü gibi, donatı akma dayanımı artırılınca $\mathrm{M}_{\mathrm{p}} / \mathrm{M}_{\mathrm{r}}$ oranlarının alt sınırı 1.4 olmaktadır. Bu durumda Deprem Yönetmeliği'nde önerilen 1.4 çarpanının güvenli sonuç vermediği ve bu çarpanın artırılması gerektiği söylenebilir. Bu konuda bir karara varmadan önce ülkemizde üretilen donatı çeliği ile ilgili yapılmış deneysel bir çalışmaya göz atmakta yarar vardır. Bu çalışmada S420 donatı çeliğinden alınan 1698 numuneye çekme deneyi uygulanmıştır. Deney sonuçları değerlendiğinde numunelerin yaklaşık \%10'unda $\mathrm{f}_{\mathrm{y}}>1.3 \mathrm{f}_{\mathrm{yk}}$ ve $\% 20$ 'sinde ise $\mathrm{f}_{\mathrm{y}}>1.2 \mathrm{f}_{\mathrm{yk}}$ olduğu gözlenmiştir[3]. Bu istatiksel çalışmadan elde edilen sonuçlar ve Şekil-2 göz önüne alındığında, çarpanın en az 1.5 olmasının daha uygun olacağı sonucuna varılmıştır

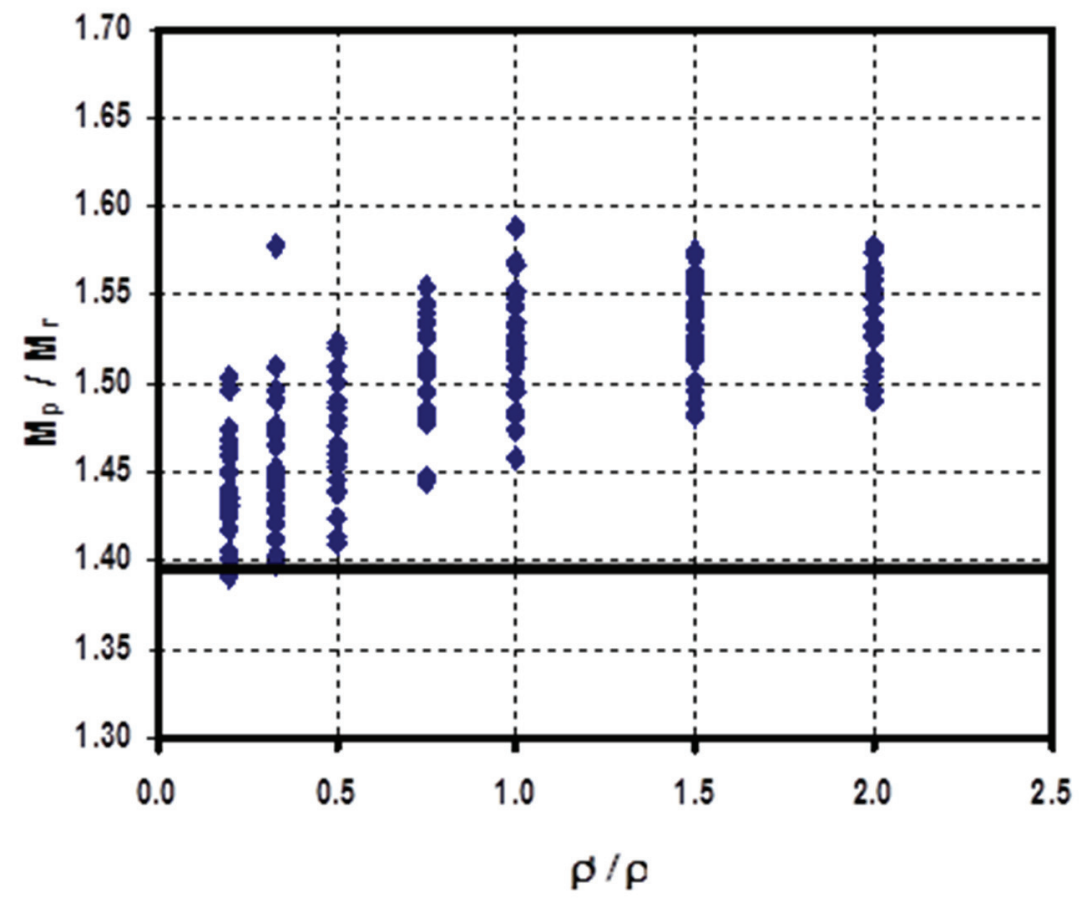

Şekil 2. $M_{p} / M_{r}$ oranının $\rho^{\prime} / \rho$ oranı ile değişimi

\section{DIKEDÖRTGEN KOLON KESITLERININ KAPASITE MOMENTI MP’NIN YAKLAŞIK HESABI}

Türk Deprem Yönetmeliği'nde en büyük kolon kesme kuvveti hesaplanırken birleşimdeki kirişlerin kapasite momentlerinin kullanılmasına izin verilmektedir. Güvenli tarafta kalacak daha basit bir hesap yöntemi olarak da kesme kuvveti hesabında kolon kapasite momentlerinin temel alınabileceği belirtilmektedir. Aynı yönetmelikte kolon kesitlerinin kapasite momentlerinin yaklaşık olarak kolon kesitin taşıma gücü momentinin 1.4 ile 
çarpılması ile hesaplanabileceği belirtilmektedir. Şekil-3'te çeşitli kolon kesitlerinin kapasite momentlerinin taşıma gücü momentine oranının $\left(\mathrm{M}_{\mathrm{p}} / \mathrm{M}_{\mathrm{r}}\right)$ beton dayanımına göre değişimi gösterilmiştir. $\mathrm{M}_{\mathrm{p}}$ hesaplanırken donatı akma dayanımı $1.3 \mathrm{f}_{\mathrm{yk}}$ alınmıştır. Şekil-3'te boyuna donat1 oranı $\rho_{\mathrm{t}}=0.01-0.026$, eksenel yük düzeyi de $\left(\mathrm{N}_{\mathrm{d}} / \mathrm{A}_{\mathrm{c}} \mathrm{f}_{\mathrm{ck}}\right)$ 0.1-0.4 olan kesitler ele alınmıştır. Şekilden görülebileceği gibi $\mathrm{M}_{\mathrm{p}} / \mathrm{M}_{\mathrm{r}}$ oranı yaklaşık 1.2 ile 1.8 arasında değişmektedir. Depremde kolona etkiyen en büyük kesme kuvveti $\mathrm{M}_{\mathrm{p}}$ ile hesaplanacağından, yaklaşık hesapta $\mathrm{M}_{\mathrm{p}}=1.4 \mathrm{M}_{\mathrm{r}}$ yerine $\mathrm{M}_{\mathrm{p}}=1.5 \mathrm{M}_{\mathrm{r}}$ veya $\mathrm{M}_{\mathrm{p}}=1.6 \mathrm{M}_{\mathrm{r}}$ kullanılmasının daha uygun olacağı söylenebilir.

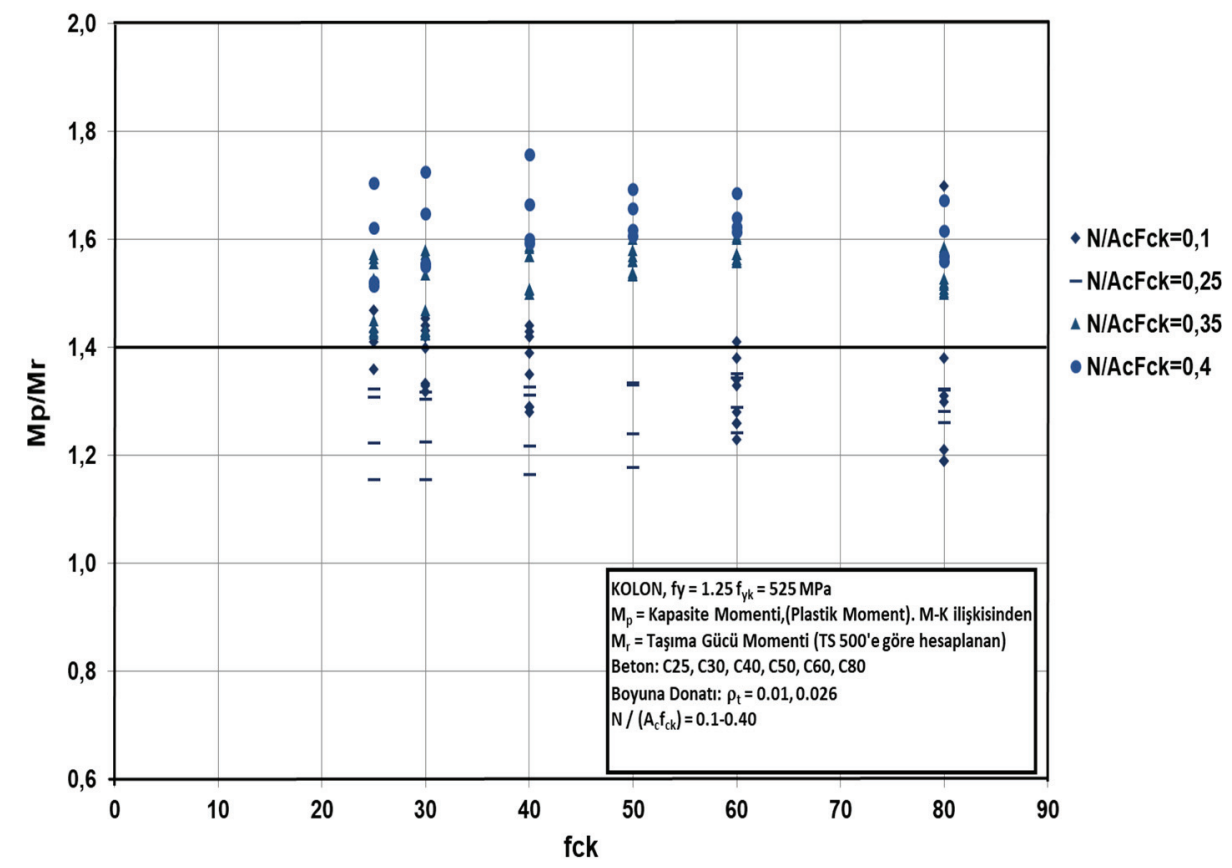

Şekil 3. Kolonlarda $M_{p} / M_{r}$ oranının beton dayanımına göre değişimi

\section{SONUÇ}

$\mathrm{Bu}$ çalışmada kiriş ve kolon kesitlerinin kapasite momentlerinin taşıma gücü momentlerine oranı irdelenmiştir. Kapasite momentleri moment-eğrilik ilişkisinden, donatı akma dayanımı \%30 artırılarak hesaplanmıştır. Taşıma gücü momentleri ise TS 500'e göre hesaplanmıştır. Elde edilen sonuçlar aşağıda özetlenmiştir.

- Kiriş kesitlerinde kapasite momentinin taşıma gücü momentine oranı yaklaşık 1.4 ile 1.6 arasında değişmektedir. Deprem Yönetmeliği'nde bu oranın 1.4 alınması önerilmektedir. Yazarlar oranın 1.5 olmasının daha uygun olacağı kanısındadır.

- Kolon kapasite momentinin taşıma gücü momentine oranının yaklaşık 1.2 ile 1.8 arasında değiştiği gözlenmiştir. Deprem yönetmeliğinde bu oran 1.4'tür. Yazarlar oranın 1.5 veya 1.6 alınmasını önermektedir. 


\section{Semboller}

$\mathrm{A}_{\mathrm{c}}$ - beton kesit alanı

$\mathrm{A}_{\text {st }}$ - kesitteki toplam donatı alanı

$\mathrm{b}$ - kesit genişliğ

$\mathrm{d}$ - kesitin faydalı yüksekliği

d' - basınç donatısının kesit kenarına olan uzaklığ 1

$\mathrm{f}_{\mathrm{cd}}-$ betonun hesap basınç dayanımı

$\mathrm{f}_{\mathrm{ck}}$ - betonun karakteristik basınç dayanımı

$\mathrm{f}_{\mathrm{y}}$ - donatı çeliği akma dayanımı

$\mathrm{f}_{\mathrm{yd}}$ - donatı çeliği hesap akma dayanımı

$\mathrm{f}_{\mathrm{yk}}$ - donatı çeliği karakteristik akmadayanımı

$\mathrm{M}_{\mathrm{p}}$ - betonarme kesitin kapasite momenti

$\mathrm{M}_{\mathrm{r}}$ - kiriş kesitinin taşıma gücü momenti

$\mathrm{N}_{\mathrm{d}}$ - kesite uygulanan eksenel kuvvet

$\rho$ - kiriş çekme donatısı oranı

$\rho^{\prime}$ - kiriş basınç donatısı oranı

$\rho_{\mathrm{t}}-$ kesitteki toplam donatı oranı

\section{Kaynaklar}

[1] “Deprem Bölgelerinde Yapılacak Binalar Hakkında Yönetmelik," Bayındırlık ve İskan Bakanlığı, 2007, Ankara

[2] Ersoy, U., Özcebe, G., "Betonarme” Evrim Yayınları, 2001, İstanbul

[3] M., Tangüler, "Yapı Denetim Sistemi Kapsamında Elde Edilen Çelik Çekme Deney Sonuçlarına Dair Bir İrdeleme,” İMO Mühendislik Haberleri 481, Ankara, 2014 
